\title{
Historic Approaches to Sonic Encounter at the Berlin Wall Memorial
}

\author{
Pamela Jordan
}

Amsterdam Center for Ancient Studies and Archaeology (ACASA), Department of Archaeology, University of Amsterdam, 1012 XT Amsterdam, The Netherlands; p.f.jordan@uva.nl

Received: 1 April 2019; Accepted: 4 July 2019; Published: 16 July 2019

\begin{abstract}
Investigations of historic soundscapes must analyze and place results within a complex framework of contemporary and past contexts. However, the conscious use and presentation of historic built environments are factors that require more deliberate attention in historic soundscape analysis. The following paper presents a multimodal research methodology and promising preliminary results from a study at the Berlin Wall Memorial in Berlin, Germany. Here, the historic context from the Wall's recent past is presented within the surroundings of the contemporary unified capital city. The study approached the past soundscape and present site by combining historic and current-conditions research, linking archival research, conditions assessments via binaural recording and psychoacoustics analysis tools, and soundscape surveys rooted in standardized soundscape research practices. In so doing, archival textual and pictorial sources provided a rich source of primary information integrated within the study and are suggested as a resource for similar inquiries elsewhere. The investigation identified concerns specific to heritage sites that require critical consideration for historic soundscape research of the recent past-survey-participant composition and the problematized use of typical descriptors in soundscape surveys are the two concerns that are discussed. Some standardized soundscape terminology and research methodologies were found to be insufficient in historic contexts. Initial qualitative results from the research are presented as a proof of concept for the research approach with signposts for future analysis and developments.
\end{abstract}

Keywords: historic soundscapes; Berlin Wall; archives; soundscape survey; memorial; architectural conservation; sound mapping

\section{Introduction}

Historic soundscape research is expectedly intricate due to its focus on past, seemingly intangible or vanished sensorial conditions. But for many such projects, the investigation also requires an additional level of attention due to the official designation of the site as historic. When a research setting is recognized by a community or society as a location of important cultural heritage, due consideration must be paid to how it is and has been presented: through changes in the interpretation of physical fragments for visitors, in (changing) conservation decisions through time, and in the active presentation choices of parts or the whole as specifically representative of historic events, experiences, or cultural significances. The historic context of heritage sites should not be assumed to be a passive condition but rather the result of choices by a select group of stakeholders with specific results in mind, be they pedagogical or recreational, that are then upheld by a user group that buys into and supports historic designation. Historic sites do not simply "happen". The many factors that construct such locations all affect the built environment as well as the soundscape. Beyond simply recognizing changes in acoustic properties and sound sources over time, the influence of intention and expectation on perception is also an important factor for historic soundscapes [1,2]. Such physical, organizational and personal factors form an important contextual layer that is not addressed in standard soundscape investigation 
practices and is rarely addressed directly in soundscape research [3,4]. Sonic elements have been previously acknowledged as potentially defining and unifying for a community through time $[5,6]$; however, the particular agency of acknowledged historic spaces-and the vital layers of additional experiential, cultural and administrative context these deliver-requires more direct attention as soundscape investigation continues to be standardized.

One way to situate an historic level of consideration for soundscape purposes is to compare the research requirements at sites created in different time periods. Research may draw from multiple devices in the soundscape toolbox, including contemporary soundwalks, measurements, interviews with varying approaches, historic documentation sources, and even reconstructions of past physical conditions. The investigatory approach where existing building remains are supported by limited original contextual information (such as an ancient building complex $[7,8]$ ) would necessarily require alternate source material and methodologies from research at a site where living witnesses to significant history still are able to provide recollected testimony to past sonic conditions. Historic or event ancient documentation may exist and give relevant information concerning past sonic environments. Such evidence can be secondary to the document's original intentions; in such cases, the origin and author of the document must be interrogated as to their motivations, societal licenses and reliability. Such distinctions are particularly important towards acknowledging whom is arranging the pieces in constructing historic narrative of place and thus whom is being given voice in presenting information about "the" past [9]. Considering soundscape in historic locations also depends on the depth of historical information available concerning sonic aspects and what roles the soundscape played in the historic past.

The variability in contextual information sources, as well as the required research methodologies for investigating them, underscores the particular difficulty to researching soundscapes within overt cultural heritage contexts: a standardized approach based on contemporary settings alone may be insufficient. This was the starting position of the presented research project, which augmented a standardized soundscape research methodology at the Berlin Wall Memorial (hereafter: Memorial) with the addition of heritage-inflected components. The purpose was to test whether the heritage context would change the responses of soundwalk participants by exploring associative meaning related to history. Would participants link the soundscape of the present as somehow meaningful and/or representative of past conditions? One avenue of inquiry was to trace whether and how participant impressions changed with the introduction of historic contextual information and narratives. Participants were first asked to analyze the sensory environment at each study location without any input from the soundwalk guide to gather their first impressions; later, some information about the historic sonic environment was recounted, after which participants were again asked to note their impressions of the sonic environment.

It was also a goal of the investigation to observe how participants responded to the heritage concepts integrated as descriptors within the public soundwalk and survey portion of the study-such as "authentic" and "significant" — and to see if any patterns arose. The resulting observations were considered a proof of concept: namely, that historic context indeed plays a role in people's perceptions of the soundscape. As the paper will show, the complexity of this role remains open for more extensive study within soundscape research; the methods utilized at the Memorial illustrate some requirements and potentials of multimodal historic soundscape work with specific regard to memorials of recent history, that is, heritage locations of the recent past with an overtly pedagogical thrust to their presentation and management [10]. Such sites afford the opportunity to combine tools available to soundscape researchers with new approaches informed by historic and architectural research. The methodology explored at the Memorial specifically demonstrates the potential of integrating archival material as a primary source of historic soundscape information. It also validates the applicability of systematic psychoacoustic mapping of the current conditions as a way to corroborate qualitative analysis. Lastly, the work highlights the strong potential for participant-based field surveys 
while also demonstrating the need for augmenting such standardized tools depending on the historic context and suggestions for such changes.

\section{Materials and Methods}

\subsection{The Memorial Today}

From 1961 to 1989, the Berlin Wall encircled West Berlin, following a $140 \mathrm{~km} / 87 \mathrm{mi}$ path that wove through neighborhoods, fields, and dense urban fabric alike. Since reunification, most of the large Wall portions have been removed (though a close inspection reveals that much of the associated infrastructure and non-structural traces persist [11]). One of the most intact segments to survive still stands along Bernauer Straße, a two-lane residential thoroughfare that links northern neighborhoods with the main train station and the central portion of Berlin (see Figure 1). The portion of the Wall along Bernauer Straße and the interrelated grounds on the eastern side have been made into an outdoor national Memorial to German division, including original Wall remnants, fragments of buildings that were demolished for the Wall's construction, new interpretative and commemorative elements that occasionally include sound and video playback, a new chapel, and documentation and visitor centers. The outdoor portion of the site extends along approximately $1.4 \mathrm{~km}$ of Bernauer Straße and is maintained as an open, grass-laid zone within the mostly residential corridor of the city. A small portion of the Wall has been reconstructed to include the full militarized apparatus of the Wall, including the western concrete barrier wall, the border strip and patrol road known as the 'deathstrip' and eastern barrier wall. Within this segment, the reconstructed deathstrip remains physically inaccessible to the public as a silent memorial, though visitors can peer inside. The Memorial grounds adjoin the Sophien Parish cemetery to the southeast, an active cemetery with internments and distinctive gravesite tending. Bernauer Straße itself is highly transited, with electric trams passing every three to five minutes, regular vehicle, pedestrian and bicycle circulation, and steady private and public tour bus traffic, particularly during the summer season. Several smaller residential streets bisect or intersect the main road. Two underground metro stations lie within the grounds, providing dense nodes of local and tourist access as well. In 2017, approximately 956,000 individuals purposely visited the Memorial grounds, with over half from outside Germany [12]. The surrounding neighborhood has an average population density of approximately 35 individuals per square kilometer [13], contributing to substantial daily circulation throughout the study area.

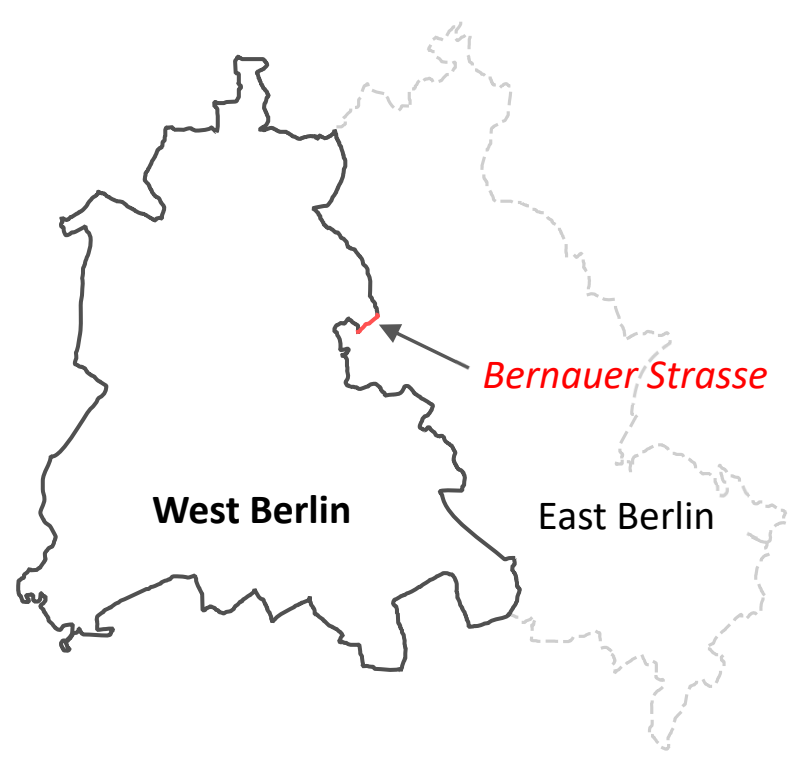

Figure 1. Location of the Berlin Wall from 1961-1989, with portion along Bernauer Straße highlighted (C) P. Jordan). 


\subsection{Sources and Methods of Historic Context Assessment}

For the purposes of this study, the relevant historic soundscape conditions that once existed at the site focused on the history being honored and presented at the Memorial—this is centered almost exclusively on the period of German division (1961-1989) and directly contributing events before and since, such as the active period of "wallpecker" ("Mauerspechte") activity, when individuals chipped off souvenir pieces of the wall for months after the initial fall of the Wall in November 1989. The study aimed to find sources of information that would reveal sonic characteristics of the site that-whether momentary or consistent over time-were historically defining in some sense. Such information would include any details directly implicating the sonic environment of the past, such as physical or architectural changes contributing to site acoustics or patterns of use, or behavior that would result in certain sonic conditions becoming routine or expected. Particular moments that were indicative of broader historic sonic realities were also sought.

With the international profile of the Berlin Wall—and the Memorial specifically—-there exists an abundance of material concerning local experience of the Wall during its operation as a militarized barrier, from news media to amateur photographs and personal letters. The chief source of information utilized was the archive of the Memorial Documentation Center, which holds photographic, audio-visual, and textual material related to the Wall's history with a local focus on the history of Bernauer Straße. A major contribution of primary information was also found in the living witness (Zeitzeuge) collection, which houses dozens of interviews with individuals who lived and/or worked along Bernauer Straße during division. The accounts of daily life and particular events therein were related during free-form interviews conducted primarily by employees of the Berlin Wall Foundation in the early $2000 \mathrm{~s}$. Witnesses included residents on the West and East, guards and Eastern border personnel, and resident nuns in the Sophien Parish located in the West that looked out over the Wall and the Sophien Parish cemetery in the East. While not explicitly about the sonic past, valuable information was nonetheless gleaned from these interviews, such as the following excerpts (from the Zeitzeuge Collection of the Berlin Wall Foundation, translated from the original German):

"Particularly on weekends it was such that the street [Bernauer Straße] was entirely a tourist mile. [ ... ] The car horn choruses were awful. People would beep well into the night as a form of protest. For the locals who lived here and for the patients that I dealt with, it was, of course, catastrophic." ...

... "Because of this length of wall, because of this no-man's-land, the quiet allowed plants as well as animals to develop and settle in the cemetery. [... ] There was also a nightingale that practically enjoyed total silence on the one side"-Nurse at Lazarus Hospital, lived on Bernauer Straße (Interview with G. Malchow, first paragraph on page 1.f, and page 24).

"[Shouts] shattered the quiet that as a general rule prevailed. And when this quiet was interrupted by shouts, warning shots, dogs barking and the like, it was even more unusual" -Resident from eastern side of the Wall (Interview with R. Zausch, page 26).

“[W]e couldn't see Bernauer Straße. We could only hear it and would ... go down to the street to see what was going on. Our police officers were standing down there with pistols drawn to give cover for people who were coming out [of their windows]"-Resident from western side of the Wall (Interview with K. De, page 18).

First-person narratives and perspectives like the above interviews were selected over, for instance, news broadcasts from the time or other forms of historic analysis to prioritize personal experiences. Some photographic and military documentation was occasionally used to corroborate accounts given in witness testimony (see for instance [14-16] for information and representations of the construction phases of the Wall and its surveillance elements). For instance, images of the guard dogs kept on wires, vehicles with speakers attached to the roof for protest broadcasts, crowds gathering to protest or help 
save fleeing East Berliners or tourists, and West Berliners gathering in large numbers to view the East on constructed platforms, all supported stories recounted in the living witnesses archive (see Figure 2).

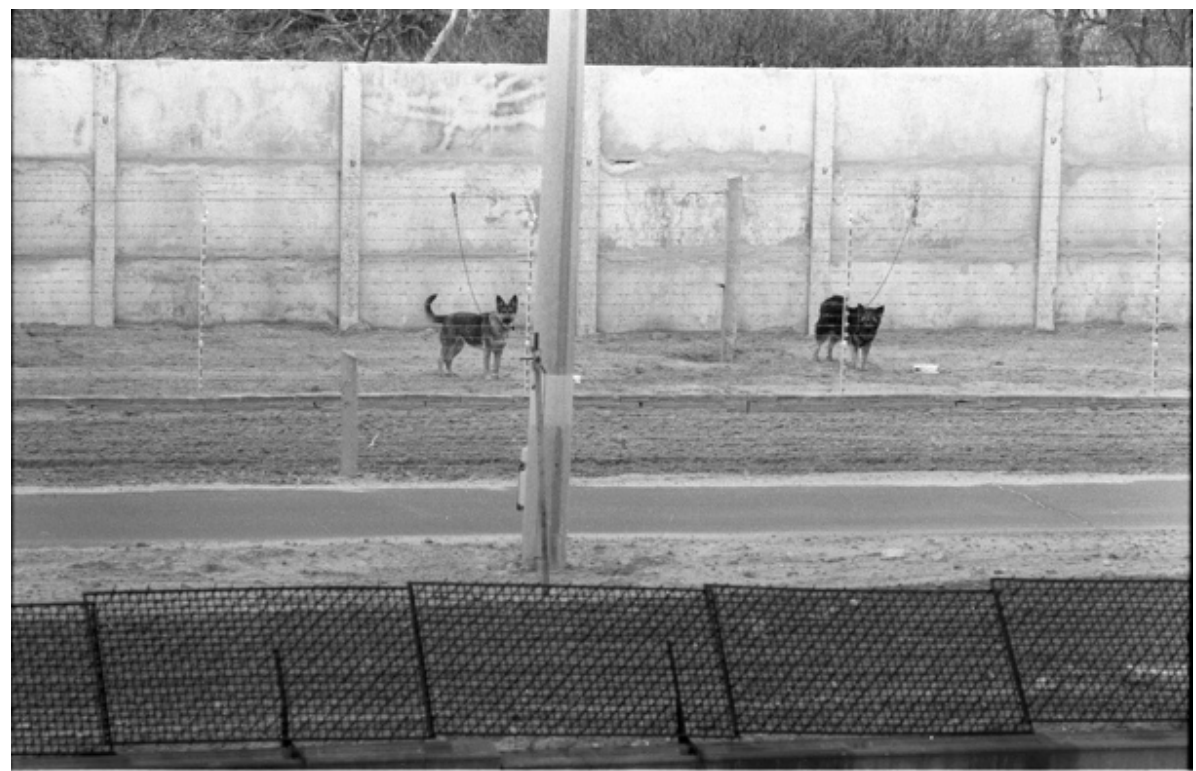

(a)

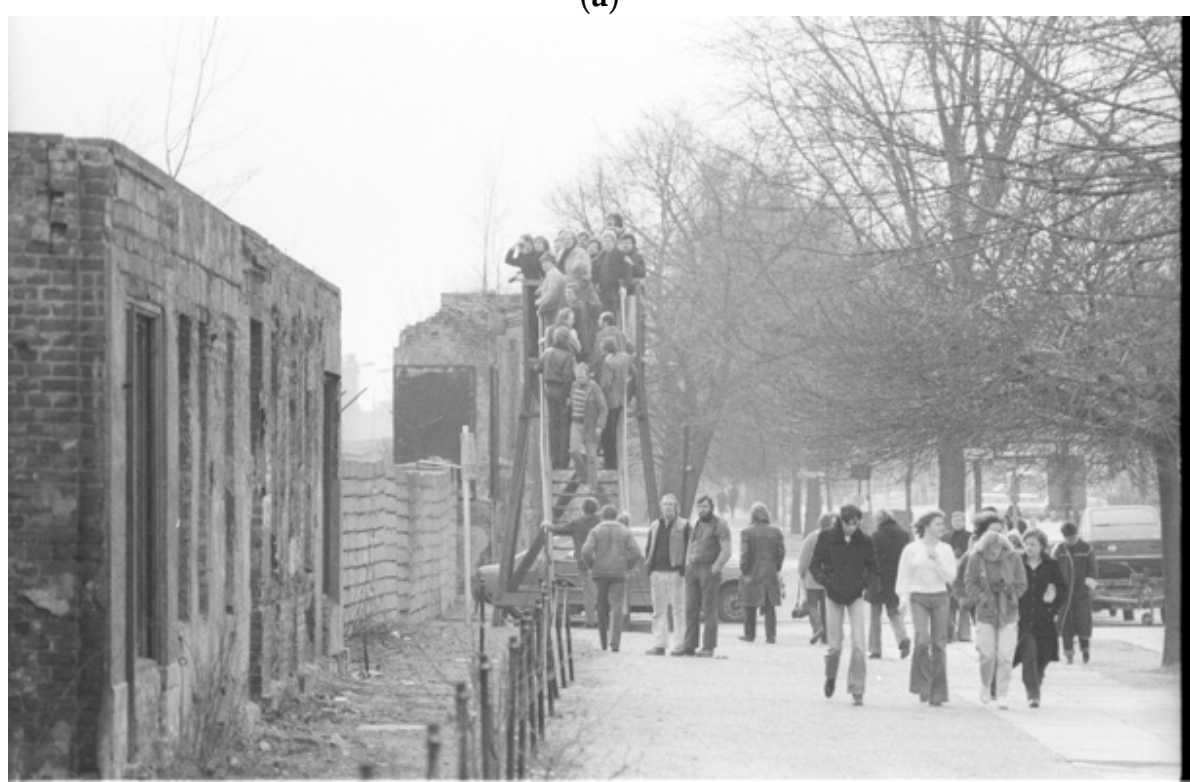

(b)

Figure 2. Images of the Berlin Wall along Bernauer Straße from the Berlin Wall Foundation archive: (a) Guard dogs kept on wire runs within the deathstrip, 1979 (C) Berlin Wall Foundation, "Hunde in Hundelaufanlage zwischen Signalzaun und Hinterlandmauer," Photo: Edmund Kaperski); (b) Lines of people using wooden platforms to peer over the Berlin Wall along Bernauer Straße into East Berlin (C) Berlin Wall Foundation, "Schaulustige und Fotografen auf einer Aussichtsplattorm in der Bernauer Straße," Photo: Edmund Kaperski).

Detailed reports made by the Eastern patrol guards of Wall repairs, protest, or political incidents and escape attempts were also consulted (housed in the Federal Archives military collection (Bundesarchiv-Militärarchiv) in Freiburg). These served to expand the comparatively limited yet vital perspective of the guards who patrolled the death-strip, as well as substantiating the anecdotal accounts of certain behaviors from the Western residents' perspectives. The physical reality of the Wall could also be traced, from the initial barbed wire and hollowed-out original building facades to 
the large concrete slabs taken down in 1989. As evidenced in pictures and personal accounts in the archives, one of the most frequently cited and thus defining sonic elements of the Wall along Bernauer Straße was the cinching of communication between East to West. With families divided on either side, every iteration of the Wall increasingly restricted direct communication across its seized land.

Research revealed a sonic history along Bernauer Straße prior to the creation of the Memorial that could be divided into periods of essential activity:

- 1961-1962: the initial construction phase, when protests and escape attempts dominated and the initial barbed wire was continually "upgraded" until a West and East Wall enclosed what became known as the death strip;

- 1962-1965: escape attempts continued, protests were common and tourism became prevalent;

- 1965-1975: the sheared-off building facades functioning as the West Wall were replaced by concrete barriers, development on the West rendered the once commercial/residential mix into a purely residential neighborhood, and protest and tourism continued;

- 1975-1989: the "final" version of the Wall was installed, animal life flourished in the cemetery and tourism and protest diminished; and

- 1989-1990: when the Wall "fell" and wall-peckers slowly disintegrated the Wall's remains for souvenirs day and night.

Significant, defining events within the timeframes above were noted. Understanding the periods when certain sonic connections were severed and other expressions were introduced on Bernauer Straße proved vital to identifying the changing (soundscape) dynamics of this cleaved neighborhood and what role sound played as either a direct actor or an expression of those dynamics. The gathered information was then applied towards designing a soundwalk and survey with reference to as much of the historic sonic conditions as possible.

\subsection{Current Context Assessment Approaches}

\subsubsection{Binaural Recording and Mapping}

Concurrent with archival research, a survey of the current soundscape was conducted using binaural recording and psychoacoustic analysis tools as advised in standardized soundscape work [4] in order to gain a clear understanding of the average sonic conditions faced by Memorial visitors today. The equipment used for field recordings was chosen for ease of use in outdoor exposures over extended periods of time without a power source. Recordings were made using the handheld SQobold II recording system paired with binaural headset (binaural microphones worn as headphones) by HEAD acoustics $\mathrm{GmbH}$; a GPS receiver was attached that linked each recording with geolocation data. Binaural recording technology logs a 360-degree fingerprint of the sonic environment that can be analyzed for physical and perceived qualities while additionally serving as a high-fidelity documentation mechanism for producing data that can serve future reference and analysis.

As the entire $1.4 \mathrm{~km}$ Memorial grounds are too large for comprehensive study, a portion was chosen that represented the region where the majority of tourists visit. This portion extends between the new Chapel of Reconciliation to the north and the Nordbahnhof metro station at the southern end of the Memorial (see Figure 3). Situated in the middle lies the reconstructed portion of the Wall and deathstrip, which is the primary destination for tourists and is observable from the ground or a viewing platform above.

Within this area surrounding the reconstructed deathstrip, fifty points were identified in a loose grid spread evenly across the terrain and just outside the Memorial grounds, including the adjacent cemetery, sidewalks and side streets (see Figure 4). Recordings of three-minute duration were made at each location every day for a week, always facing Bernauer Straße (depending on which side of the street the point was located, this could result in the researcher facing east or west). Over 350 recordings were made in total. Additionally, four images were made at each recording location, one image per 
cardinal direction, to maintain a visual record of the general contextual conditions of each recording point. Positions were confirmed via the GPS readings associated with each recording.

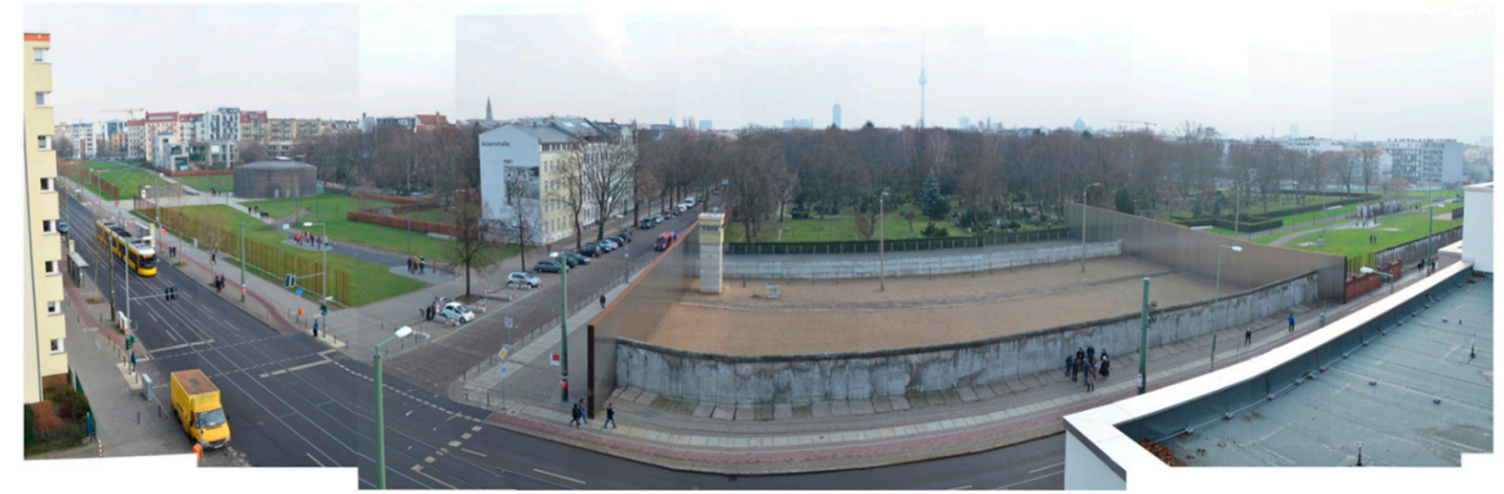

Figure 3. Overhead view of the study area within the Memorial. The Chapel of Reconciliation (round wooden building) sits at the top left, Nordbahnhof lies out of view to the far right and Bernauer Straße links these two along the bottom. In the center of the image, the conserved and reconstructed Wall and "deathstrip" with guard tower area can be seen. (Image (C) P. Jordan).
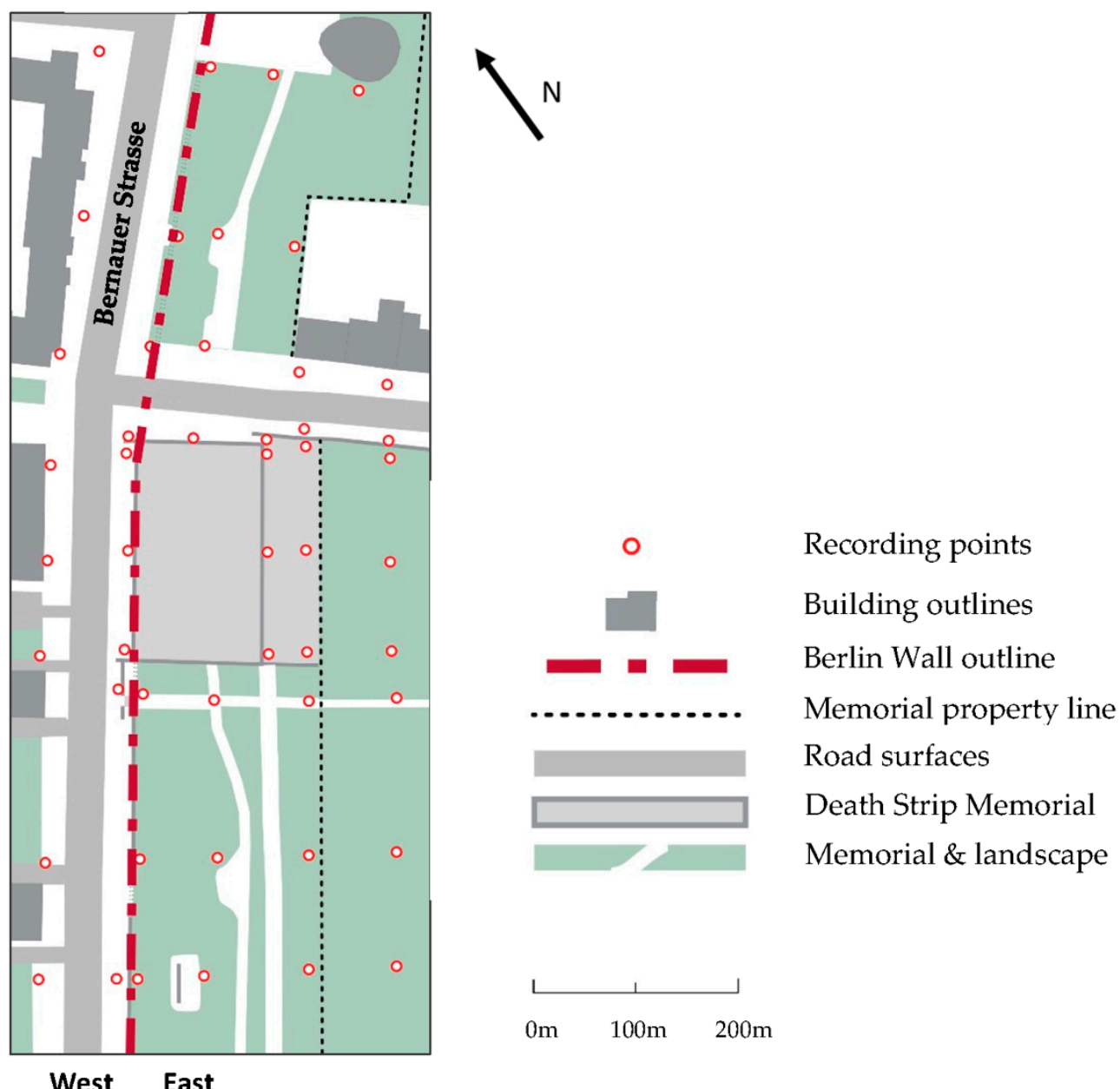

Figure 4. Sitemap of the Memorial study area with soundwalk study points highlighted. The conserved portion of the Wall and deathstrip assembly is shaded in gray at the center (C) P. Jordan).

The recordings were analyzed for certain properties-an $\mathrm{LA}_{\mathrm{eq}}$ analysis provided continuously measured $\mathrm{dB}(\mathrm{A})$ values at each point and a psychoacoustic Specific Loudness analysis provided the 
continuously measured perceived loudness in Sone (GF) at each point as well [17,18]. The values were then averaged within each recording and then across the seven days of recordings to provide representative values of a typical summer day (high visitor season). The results were mapped over a simplified rendering of the Memorial landscape to observe any unusual sonic pockets or relationships within the landscape that might have historic significance, depicted and discussed in detail in Section 3.

\subsubsection{Soundwalks with Custom Surveys}

The information derived from the archival research and the mapping study informed the design of a customized soundwalk and survey to investigate whether and how visitors connected the current soundscape to the history of the place. Five study points were selected that reflected, as much as possible, a diverse set of current and historical conditions, including perspectives from West residents, East residents, and guards. The following positions were identified for study (see Figure 5a-e for representative images):

a. "Mundt": Located on the west side of the Wall, today in an open area dominated by traffic noise from the adjacent intersection. Adjacent Wall fragments are not conserved and appear as they looked after the Wallpeckers finished their work in 1990. The Eastern landscape can be seen easily. Historically, this location was a bend in the original Wall where the killing of Ernst Mundt in 1962 (as he tried to escape from the East) became a political flashpoint. It was later a spot where Western residents attempted suicide by crashing their cars into the concrete wall.

b. "Deathstrip": Located on the East side of the Wall in the midst of the large grassy expanse that dominates the interpreted deathstrip landscape. Generally visually isolated from the West by the original Wall remnants at the street. Historically a part of the original Sophien Parish cemetery that was converted into a denuded area with guard dogs, tripwires, sirens and constant vehicle patrols by the East German guards.

c. "West Wall": Located on the West, today directly in front of the conserved portion of the concrete West Wall that faces the documentation center on the other side of Bernauer Straße, a major crossroads for tourist circulation and dominated by dense vehicle traffic noise refracting between non-porous surfaces (effectively creating a semi-closed urban canyon). No portion of the East can be seen except the tops of trees and buildings. Historically resembles the Wall as it appeared from 1975 onward. Part of the path along which tourist buses and cars honking in protest would travel while the Wall was in use.

d. "East Wall": Located on the East, today in the back area of the conserved portion of the Wall, dominated by the sound of crushed stone underfoot and echoes from Bernauer Straße. No part of the Western streetscape can be seen except the tops of buildings; the top of a guard tower is visible within the deathstrip area and the deathstrip itself can be viewed through gaps left in the Eastern Wall. Historically resembles the eastern portion of the Wall as it appeared in 1965 (though the aforementioned gaps are a modern intervention) and sits adjacent to the Sophien Parish cemetery that was also present throughout the Wall's historic use.

e. "Chapel": Located on the eastern edge of the Wall next to the grassy expanse of the interpreted deathstrip and facing the newly constructed (2000) Chapel of Reconciliation. The West can easily be seen and heard through a modern "Wall" interpretation. Located within the grounds of the Church of Reconciliation foundations (demolished in 1985), next to buildings where people attempted to escape from their windows in the first year of the Wall's construction and where building facades functioned as the Wall itself for many years before being replaced with concrete slabs in the 1970s. 


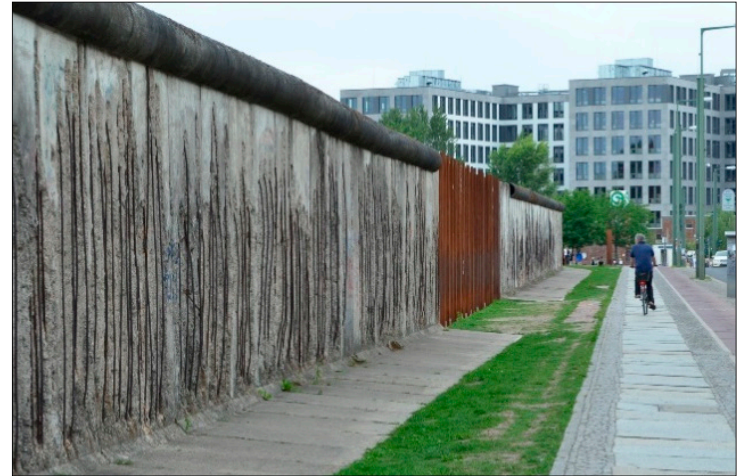

(a)

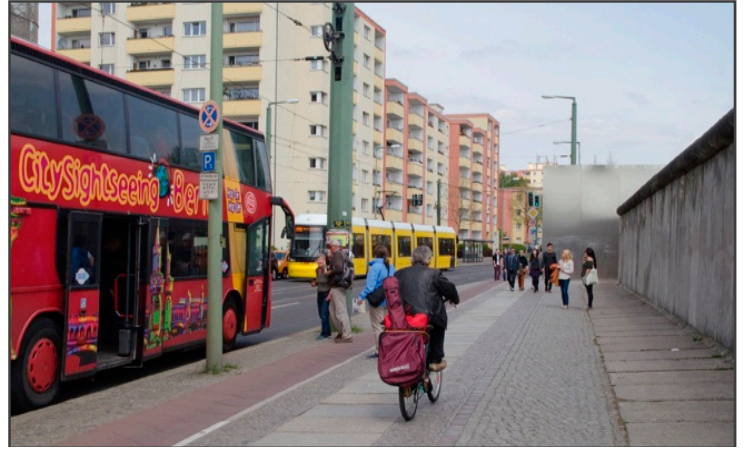

(c)

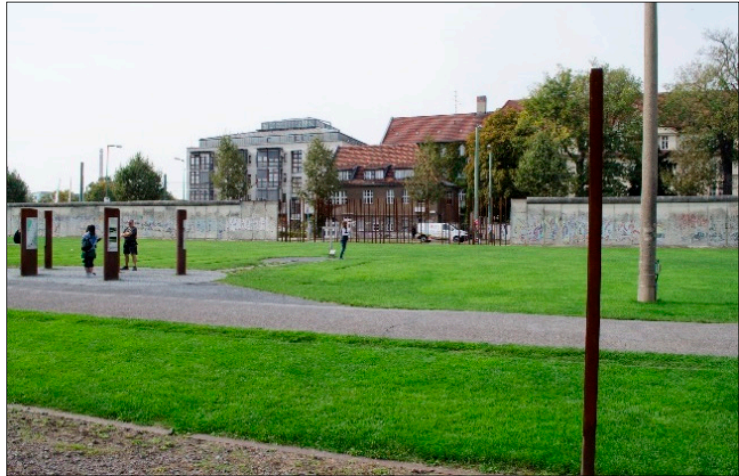

(b)

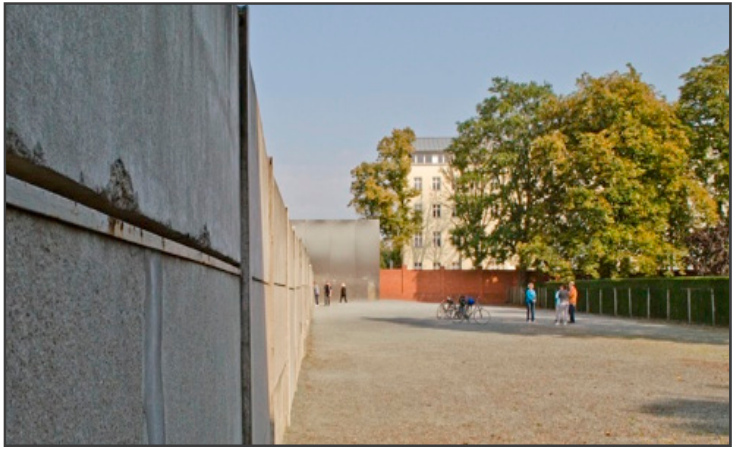

(d)

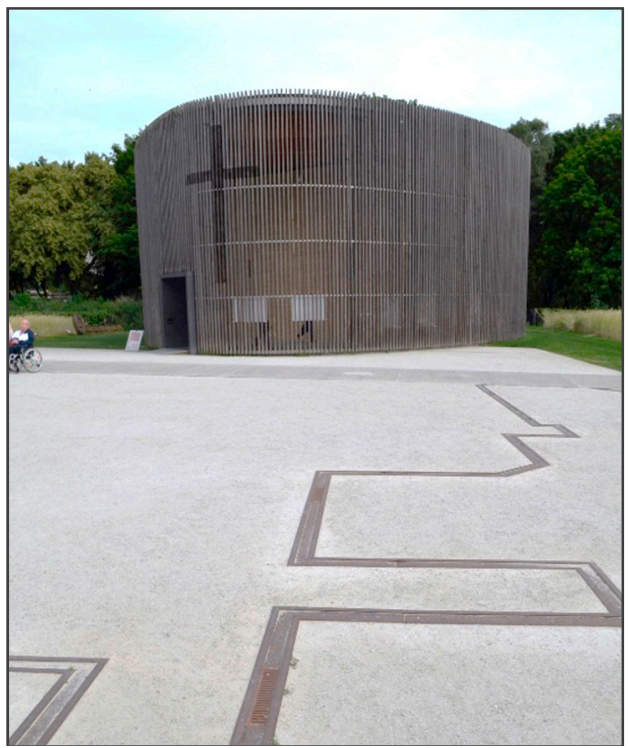

(e)

Figure 5. Images of soundscape study points (C P. Jordan): (a) “Mundt"; (b) “Deathstrip"; (c) "West Wall"; (d) "East Wall"; (e) "Chapel".

As opposed to the predisposition of many soundscape studies to focus on preference assessments $[19,20]$, the focus of the work at the Memorial was to delve into associative meaning related to history. Categorizing soundscapes according to appropriateness continues to be explored within soundscape studies [21,22] and was implemented here also, such as the integration of descriptors such as authenticity and significance [23]. With the study locations established, the survey was designed to approach these inquiries by using a simple, standard format of twelve, five-point semantic scales using descriptor pairs [4,24]. The chosen pairs derived from earlier research on the topic of soundscape descriptors [23] and are shown in Table 1. 
Table 1. Descriptor pairs used in the semantic scales of the survey.

\begin{tabular}{cc}
\hline Acceptable & Unacceptable \\
Appropriate & Inappropriate \\
Authentic & Altered \\
Clear & Confusing \\
Comfortable & Uncomfortable \\
Constant & Changing \\
Dense & Sparse \\
Meaningful & Meaningless \\
Natural & Artificial \\
Old & New \\
Pleasant & Unpleasant \\
Significant & Insignificant \\
\hline
\end{tabular}

The semantic scales were presented on an individual sheet for each study point; the rows depicted in Table 1 were shuffled on each sheet so that no two sheets appeared the same. Additionally, the columns in Table 1 were switched for return visits. The scrambling of the scales was designed to subvert any possible primacy and recency effects during the study [25].

To the same end, participants were not told or shown the path of the soundwalk. The walk began with a short introduction about soundwalks and soundscape research, instructions about filling in the survey, and a research and confidentiality agreement. The soundwalk was conducted in English. Participants were encouraged to adopt a "holistic" hearing approach to the sonic environment rather than identifying individual sound sources [26,27]. When assessing their experience, they were encouraged to mark the sheets freely, skipping scales they felt they could not use while annotating the form with any comments and concerns. Giving participants the freedom to skip scales entirely highlighted terms that participants felt unsure employing - any change in usage during return visits (after historic context dissemination) was of interest. Requiring participants to answer every scale, as is generally done in soundscape surveys, would not reveal such usage dynamics. In a similar mode of inquiry, a free-form question was also included at the bottom of each sheet that asked simply, "What else is on your mind"?

After the introduction given by the soundwalk guide, participants were led to point 1 and asked to listen for two minutes and then record their responses on the survey sheet. When everyone had completed her or his survey form, the group was led to point 2 and the process repeated identically until point 5 . No questions related to the historic context were answered by the guide until this time. At point 5 , the study was reoriented with a briefing on the concepts underlying historic soundscapes, their evolution through time and what they can embody that physical fabric alone might miss. Specific stories and historic sonic descriptions related to point 5 were shared with the group to demonstrate the kind of information they could expect to hear from that point on and all questions were answered by the guide. Participants were then asked to listen to the soundscape for two minutes and fill out the associated survey sheet. Point 5 acted as a position of conceptual transition within the study, a setting physically and acoustically removed from the other locations in order to introduce another layer of awareness to the perspective of participants. No comparative data derived from location 5. Once finished, the group was led to point 4 and the process repeated with historic context added until point 1. In this way, points 1-4 were surveyed twice. Each group naturally broke into discussion between survey points and at the conclusion of the soundwalk, resulting in each walk lasting approximately one and three-quarters of an hour.

The study was structured so as to gain insight into participants' use of descriptors without any historic contextual information (capturing their impressions based on the immediate sensory environment alone) followed by whether the introduction of historic information and narratives would dramatically alter their impressions and subsequent responses. To examine these dynamics, the soundwalk was designed for participants to assess each study point twice: first without any 
information provided for an initial appraisal of present conditions, and then again later in the soundwalk after learning about the historic soundscape from the soundwalk guide. Information provided was specific to each location whenever possible and included historical events, descriptions and stories from the archives related to sound in some direct capacity (such as the examples in Section 2.2).

The composition of participants was a concern for this historic soundscape study. A broad and even spread among age, gender, professional background and nationalities was desired to provide a representative population sample. Given the international profile and educational mission of the Memorial, three groups in particular were sought for inclusion as well: first-time visitors to the site, long-term residents of the area and/or living witnesses, and caretakers and managers of the Memorial itself. These categories were identified to capture the impressions of the primary interest groups related to the Memorial grounds, both as an historic reality and a contemporary interpretation. In total, 27 individuals participated in the study.

\section{Results}

\subsection{Soundscape Mapping}

Analysis of the soundscape maps in Figure 6 points to Bernauer Straße as the dominant sonic component to the current Memorial landscape. Comparing the $\mathrm{LA}_{\mathrm{eq}}$ to the perceived loudness in sone does not reveal any striking differences in the objective acoustic qualities of the space with what was perceived-perceptual indicators were consistent with physical sound behavior. However, the maps do make tangible the wide range of conditions within the Memorial, particularly the differences between east and west sides of the Wall. Along Bernauer Straße, the $\mathrm{LA}_{\mathrm{eq}}$ and sone were found to be consistently high, while the measurements taken in the interpreted deathstrip landscape were often similar to those found in the cemetery beyond. Unsurprisingly, research point 4 ("East Wall") was the most sonically isolated with the lowest measured values.

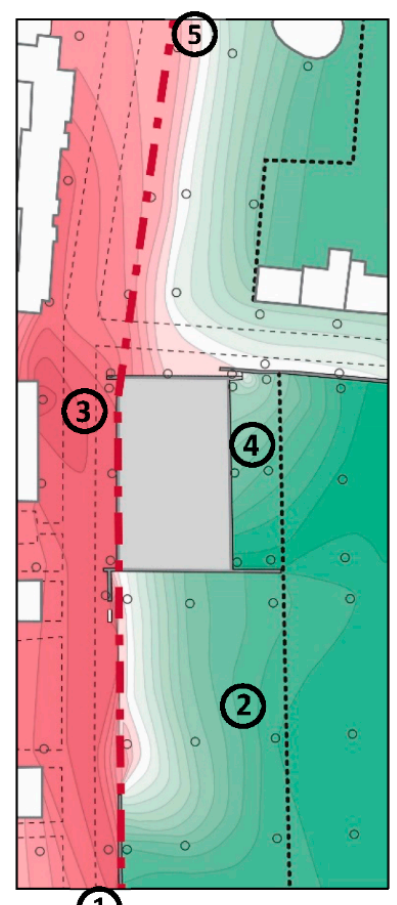

(1)
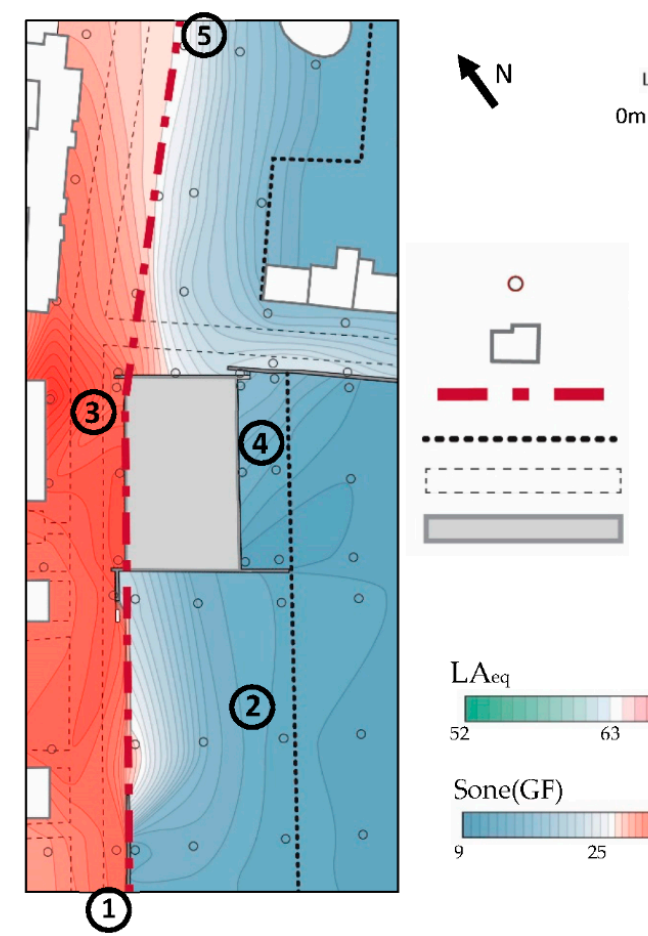

Recording points

Building outlines

Berlin Wall outline

Memorial property

Roadways

Preserved deathstrip

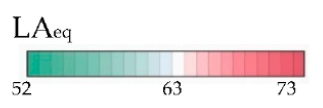

Sone(GF)

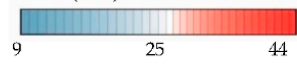

Figure 6. Soundscape maps of the Memorial on a typical summer day, measurement points in small circles, soundwalk study points in large numbered circles (C) P. Jordan): (left) LA eq values derived from FFT (Fast Fourier transform) vs. Time analyses over $3 \mathrm{~min}$; (right) averaged sone (GF) values derived from Specific Loudness analyses over $3 \mathrm{~min}$. 
The maps also clearly show two key architectural elements that enforce such different sonic environments on the East and the West of the Wall to this day. First is the Wall itself, an effective barrier that appears to absorb and/or deflect sound from Bernauer Straße. South of the preserved Wall and deathstrip area, the original concrete Wall is mostly intact. Here, the difference in measurements immediately on either side of the Wall can be large; at the southern-most measuring points, (located near point 1), a reading of $69 \mathrm{~dB}(\mathrm{~A})$ on the West is answered by only $54 \mathrm{~dB}(\mathrm{~A})$ on the East.

The second architectural element to note is the open grassy expanse that was once the deathstrip, which forms the majority of the Memorial landscape today (on the maps, this is the region between the red line demarcating the Berlin Wall and the dark dotted line indicating the Memorial property boundary). This region appears to have a significant mitigating impact on the sound emanating from the street, as can be seen by comparing the northern portion of the study area (top portion of the maps, where no fragment of the Wall remains) to the southern portions of the study area (bottom portion of the maps, where the original Wall remains). Without the tall concrete wall structure, a full spectrum of direct sounds from Bernauer Straße penetrates the open landscape but is absorbed through ground attenuation as one gets farther away from the street [28]. The concrete slabs and open landscape are both designed elements that are physically remnant of the original Wall construction during its later years. Their preservation provides authentic visual continuity of the site as whole for visitors, though the grass is materially different from the original groomed sand that was utilized by guards. As the maps illustrate, the soundscape conveys some of the most powerful messaging of the original militarized architecture, which can still be experienced at the Memorial today; the Wall and deathstrip areas continue to cut off sonic connection between East and West and produce two distinct sonic environments. How these differences manifest throughout the Memorial and are subsequently understood by visitors requires a detailed study of the soundwalk survey results.

\subsection{Soundwalk and Surveys}

The information gathered in the surveys illustrates a few key findings concerning the applicability of descriptors for historic soundscapes. At the Memorial, several descriptor pairs proved problematic for consistent use by some participants and were skipped altogether. Table 2 shows the total number of participants who did not use a semantic scale on one or both visits to a study point by each participant. The pair altered — authentic proved the most consistently avoided term across all study points.

To search for possible reasons behind these findings, instances of skipping a semantic scale were broken up between first and second visits. If a semantic scale was skipped both on first and second visits to a study location, it could indicate that the terms themselves were not found to be clear or applicable at all for participants. Table 3 shows the percentage of participants throughout the entire soundwalk who skipped a semantic scale per visit to each study point.

In Table 3, percentages are calculated based on the number of participants in each gender group across the four points studied. This results in 152 data points per visit for female participants (19 participant responses at each of four study locations per visit), 24 data points for male participants and eight data points for those who identified in the category of "other". Looking at the semantic pair Meaningful-Meaningless, for instance, the scale was left empty twice across the 152 visits by female participants on the first visit, resulting in a $2.9 \%$ skip rate for first visits throughout the walk. This scale was subsequently used by all female participants on the second visit, resulting in a $0 \%$ skip rate for second visits.

It is important to recognize the difference between percentage results given the varied number of participants in each gender group. Nonetheless, the findings point out several semantic scales that some participants chose not to apply on both first and second visits: Natural-Artificial, Altered—Authentic, Old-New, Appropriate-Inappropriate and Acceptable-Unacceptable. These choices do not indicate the value of the terms, since they were applied for the majority of the time throughout the entire study. Rather, the findings suggest ambiguities in how to conceive and apply them; several individuals voiced their confusion about the context under which authenticity should be judged, for instance. Authentic 
to whom, to what time period? Such ambiguity also may be a reason for the increase in skipping the semantic pair Natural-Artificial, a point returned to in more detail below.

Table 3 reveals a pattern concerning the use of each scale according to gender groups: an evident contrast of descriptor use exists between female and male participants. The combined female participants skipped (both on first and second visits to a study point) the five semantic scales noted above at least $10 \%$ of the time. This suggests the possibility that gender could have an influence on the determination of artificiality, authenticity, age, appropriateness and acceptability of historic soundscapes. Previous research has suggested the possibility that semantic-based scales may play a role in such assessment differences [29].

Table 2. Number of total participants (out of 27) who did not use semantic scales on the first and/or second visit to each study point.

\begin{tabular}{cccccc}
\hline \multicolumn{2}{c}{ Semantic Scale } & Mundt & Deathstrip & West Wall & East Wall \\
\hline Constant & Changing & 0 & 0 & 0 & 0 \\
Natural & Artificial & 3 & 3 & 5 & 3 \\
Altered & Authentic & 7 & 7 & 6 & 6 \\
Old & New & 4 & 5 & 6 & 4 \\
Appropriate & Inappropriate & 6 & 5 & 4 & 3 \\
Insignificant & Significant & 2 & 3 & 0 & 1 \\
Comfortable & Unsettling & 0 & 0 & 1 & 0 \\
Dense & Sparse & 2 & 2 & 1 & 0 \\
Unacceptable & Acceptable & 3 & 2 & 3 & 2 \\
Pleasant & Unpleasant & 1 & 0 & 0 & 0 \\
Meaningless & Meaningful & 1 & 1 & 0 & 2 \\
Confusing & Clear & 1 & 1 & 0 & 0 \\
\hline
\end{tabular}

${ }^{1}$ Order of descriptors were as shown or reversed, as described in Section 2.3.2.

Table 3. Percentage of participants that skipped each semantic scale on first and second visits to all four study points, organized by self-identified gender groups. Results over $10 \%$ are highlighted.

\begin{tabular}{cccccccc}
\hline & & \multicolumn{2}{c}{ Female (19 Total) } & \multicolumn{2}{c}{ Male (6) } & \multicolumn{2}{c}{ Other (2) } \\
\hline \multicolumn{2}{c}{ Semantic Scale } & 1st Visit & 2nd Visit & 1st Visit & 2nd Visit & 1st Visit & 2nd Visit \\
\hline Constant & Changing & $0 \%$ & $0 \%$ & $0 \%$ & $0 \%$ & $0 \%$ & $0 \%$ \\
Natural & Artificial & $\mathbf{1 0 . 5 \%}$ & $\mathbf{1 7 . 1} \%$ & $4.2 \%$ & $0 \%$ & $0 \%$ & $0 \%$ \\
Altered & Authentic & $\mathbf{2 3 . 7 \%}$ & $\mathbf{1 8 . 4} \%$ & $4.2 \%$ & $0 \%$ & $\mathbf{3 7 . 5 \%}$ & $\mathbf{3 7 . 5 \%}$ \\
Old & New & $\mathbf{1 5 . 8 \%}$ & $\mathbf{1 0 . 5} \%$ & $\mathbf{1 2 . 5} \%$ & $4.2 \%$ & $0 \%$ & $0 \%$ \\
Appropriate & Inappropriate & $\mathbf{1 7 . 1 \%}$ & $\mathbf{1 5 . 8} \%$ & $4.2 \%$ & $0 \%$ & $0 \%$ & $0 \%$ \\
Insignificant & Significant & $8.8 \%$ & $0 \%$ & $0 \%$ & $0 \%$ & $0 \%$ & $0 \%$ \\
Comfortable & Unsettling & $0 \%$ & $0 \%$ & $0 \%$ & $4.2 \%$ & $0 \%$ & $0 \%$ \\
Dense & Sparse & $2.9 \%$ & $0 \%$ & $0 \%$ & $\mathbf{1 2 . 5} \%$ & $0 \%$ & $0 \%$ \\
Unacceptable & Acceptable & $\mathbf{1 3 . 2 \%}$ & $\mathbf{1 3 . 2 \%}$ & $4.2 \%$ & $0 \%$ & $0 \%$ & $0 \%$ \\
Pleasant & Unpleasant & $1.5 \%$ & $0 \%$ & $0 \%$ & $0 \%$ & $0 \%$ & $0 \%$ \\
Meaningless & Meaningful & $2.9 \%$ & $0 \%$ & $0 \%$ & $4.2 \%$ & $0 \%$ & $0 \%$ \\
Confusing & Clear & $1.5 \%$ & $0 \%$ & $4.2 \%$ & $0 \%$ & $0 \%$ & $0 \%$ \\
\hline
\end{tabular}

${ }^{1}$ Order of descriptors were as shown or reversed, as described in Section 2.3.2.

When the semantic scales were employed, shifts were evident from the first and second visits in a number of cases. To analyze aggregated responses, the scales were assigned numerical values for each point on the scale. For instance, in the Constant-Changing scale, Constant was assigned a value of 1 and Changing a value of 5 . Participant responses were then assigned a number according to where they marked on the scale between these two descriptors, with 3 being a neutral answer. The results were aggregated for each study point and responses between the first and second visits were compared (see Figure $7 \mathrm{a}-\mathrm{d}$ ). 


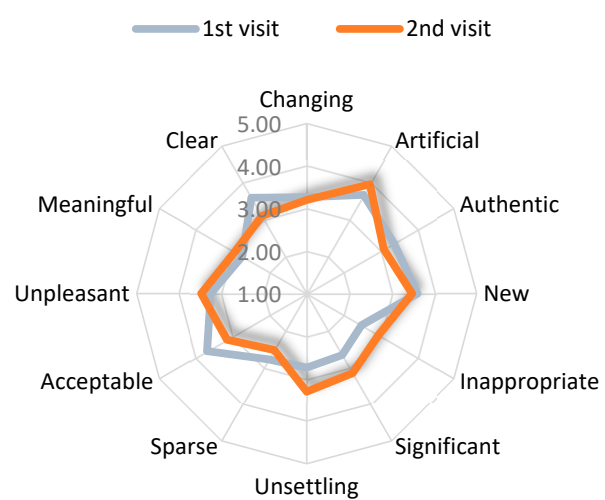

(a)

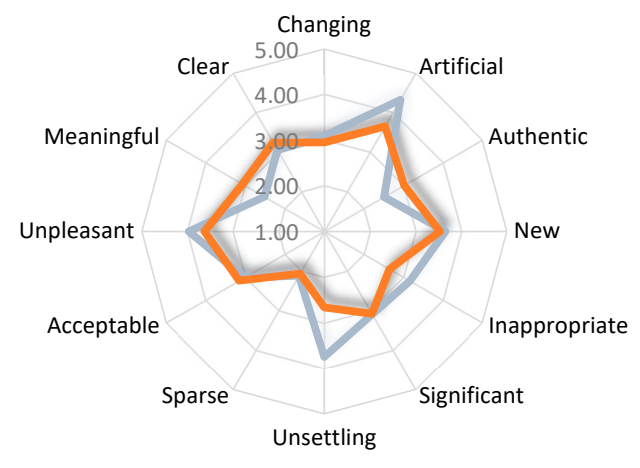

(c)

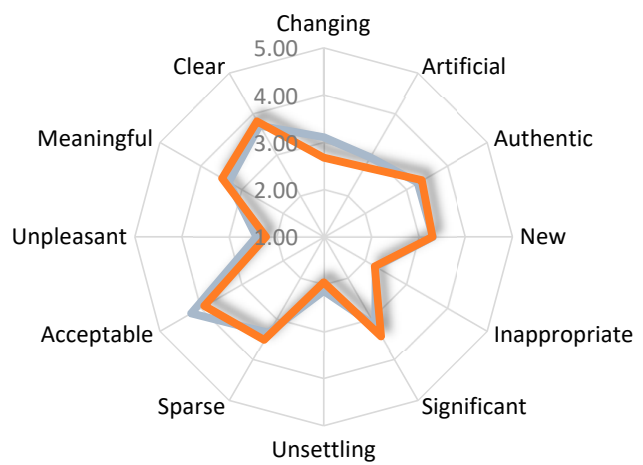

(b)

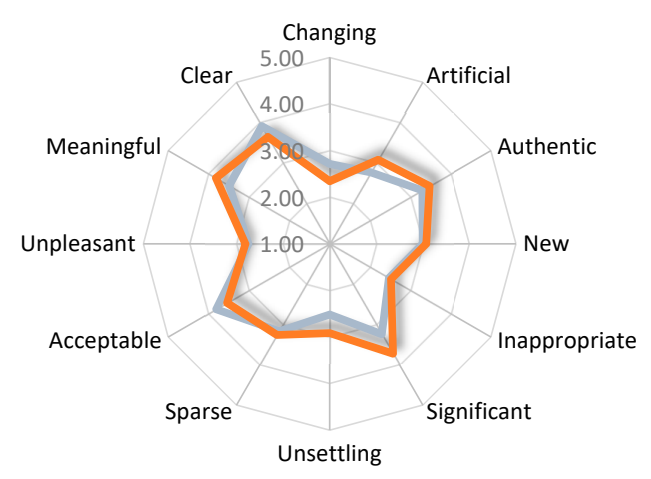

(d)

Figure 7. Web charts of average ratings given by all study participants on first (blue) and second (orange) visits to study points, where 1 is the center-point of each web (C P. Jordan): (a) "Mundt"; (b) "Deathstrip"; (c) “West Wall"; (d) "East Wall".

From the comparison charts, it is first evident that, averaged across all participants, the ratings given to the Deathstrip (b) and East Wall (d) study points shifted very little between the visits, whereas the shifts in perception of the West Wall point (c) generally tended to move similarly between participants along particular scales, notably the Calm-Unsettling, Natural-Artificial and Authentic-Inauthentic scales. One participant (a visitor) analyzed her/his impression this way on the survey sheet: "After getting information about how it was here in the past, for me it seems to be more authentic. The traffic is now more part of the history as well as the wall itself." This response was regularly echoed by other participants; it suggests that the sonic history provided the foundation for participants to re-contextualize the unpleasant, intense sonic environment as related or similar to certain historic conditions. This could explain why the average rating on the second visit found the West Wall to be less unsettling, more authentic and indeed more "natural".

In order to determine whether the relatively stable responses at (b) and (d) above were due to similarities in response or the averaging of disparate responses, the results were analyzed per individual and by degree of perception shift: whether the values given on a scale on the second visit shifted by $25 \%$ or more, between $0-25 \%$ or not at all. Table 4 examines how often participants shifted at least six of the twelve scales at each study point. 
Table 4. Table showing the number of instances that perceptions shifted between the first and second visit at each study point (of 27 participants).

\begin{tabular}{ccccc}
\hline The Value of at Least Half of Semantic Scales: & Mundt & Deathstrip & West Wall & East Wall \\
\hline Shifted by $25 \%+$ & 14 & 12 & 10 & 12 \\
Shifted by 0-12\% & 5 & 7 & 9 & 6 \\
No change & 4 & 1 & 6 & 1 \\
\hline
\end{tabular}

The results of Table 4 illustrate that, while the West Wall indeed was a position of noticeable shifts in perception by participants, it was not the most extreme. Noticeable shifts across several scales took place for participants throughout the soundwalk: at every study point, at least 10 participants changed six or more of their answers by at least $25 \%$. Perceptions appear to have shifted dramatically at the Deathstrip and East Wall study points in particular. However, participants did not always agree in the direction of such shifts, leading the averaged results in Figure 7 to appear rather stable. This observation was exemplified by a conversation between two participants after the conclusion of a soundwalk, in which their perception of the quieter locations (i.e., East Wall and Death Strip) shifted as a result of the soundwalk but in opposite directions: one found the quiet and park-like settings more soothing after learning about the history, while the other participant read them as disjointed and even disturbingly misrepresentative in a place of historical trauma.

Future validation of these results would also be able to trace whether subtler patterns of perceptive shifts exist in conjunction with specific factors-undeniably, multiple aspects contribute to such shifts. When investigating heritage sites, the participant's direct knowledge of its history may be a critical factor. There are multiple paths towards measuring such pre-existing participant knowledge; linked professional expertise (such as history, politics or city planning) and personal background (such as being part of a group directly affected by the associated history of the site) are two examples that could be easily probed within a survey. At the Berlin Wall, partly due to its international notoriety, it is also still possible to divide participants between those with living memory of the Wall's fall and those without by looking at their age. Consequently, the participant responses were compared between those 35 years old and older (i.e., individuals who were at least 10 years old when the Wall fell) and those 34 years old and younger to see if age played a noticeable role in any shifts.

The results in Figure 8 point to some possible differences between age groups. The groups vary in their descriptions of each point according to the scales-the most similar are Mundt and the Deathstrip points, where the second visit webs look very similar. The responses by the older group generally show very similar impressions on the first and second visits, while the younger group shows somewhat more varied responses on the second visit. The exception to this dynamic is the West Wall point, where some perceptions shifted in both groups. Thus, it appears that age may provide useful nuance when reading the survey results-a larger sample size is required to confirm and outline such connections meaningfully. At this stage, the results point to the possible influence of age on participant perception as well as the influence of historic information in less pleasant study points.

The open question at the bottom of each sheet proved helpful in capturing some details of the shifts in perception that some participants experienced during the soundwalk. Numerous individuals noted a connection between people's perception of sound joined with historic conditions:

"The information about the sonic history of the site influences the listening to the actual sounds. The noise today seems indifferent; other than the 'historical noise' with a certain intention/meaning." (Memorial staff)

“There's a gap between my acoustic imagination (gun shots, church bells, protests ... ) and the actual sounds I can hear. The combination is interesting." (Memorial staff)

"The wall is silent; the wall produces silence in passersby. It is a powerful thing to sense the wall in such proximity. It is unsettling that it still shapes the space in such powerful ways." (visitor) 
"[I am] more aware of hum of park-wind in trees, and birds.... I have a very different attention now that I have more narratives about the space." (visitor)

A fuller understanding of the scalar survey results was possible using the information provided in the open question responses, supporting the utility of such free-form options in historic soundscape surveys of this type.

Participants under 35 years old (16 total)

(a)

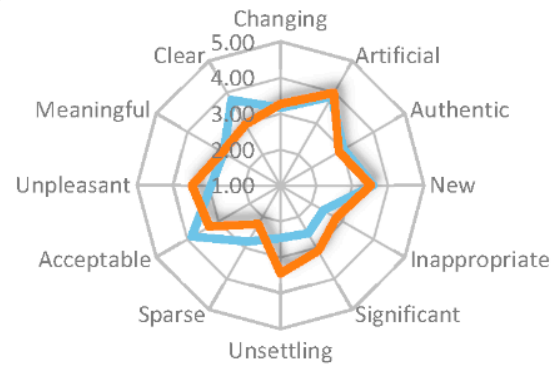

(b)

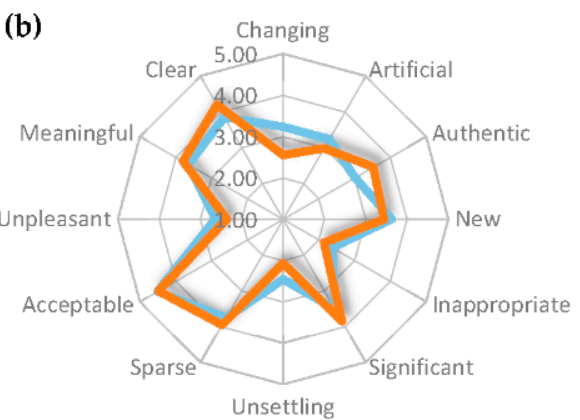

(c)

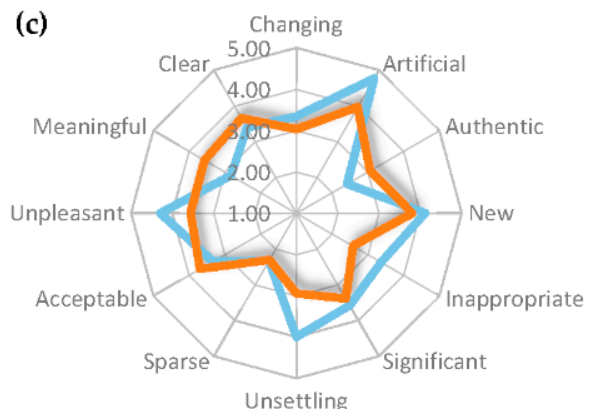

(d)

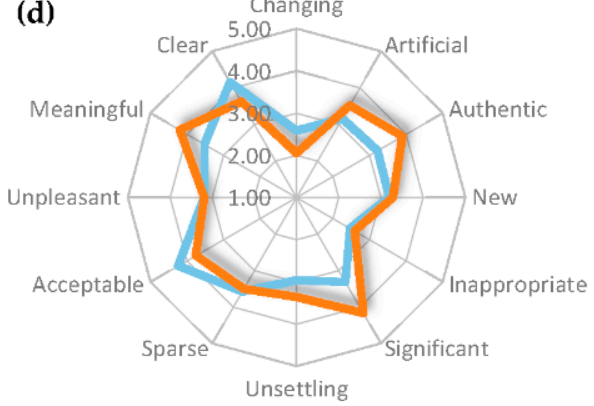

\section{Participants over 35 years old (11 total)}
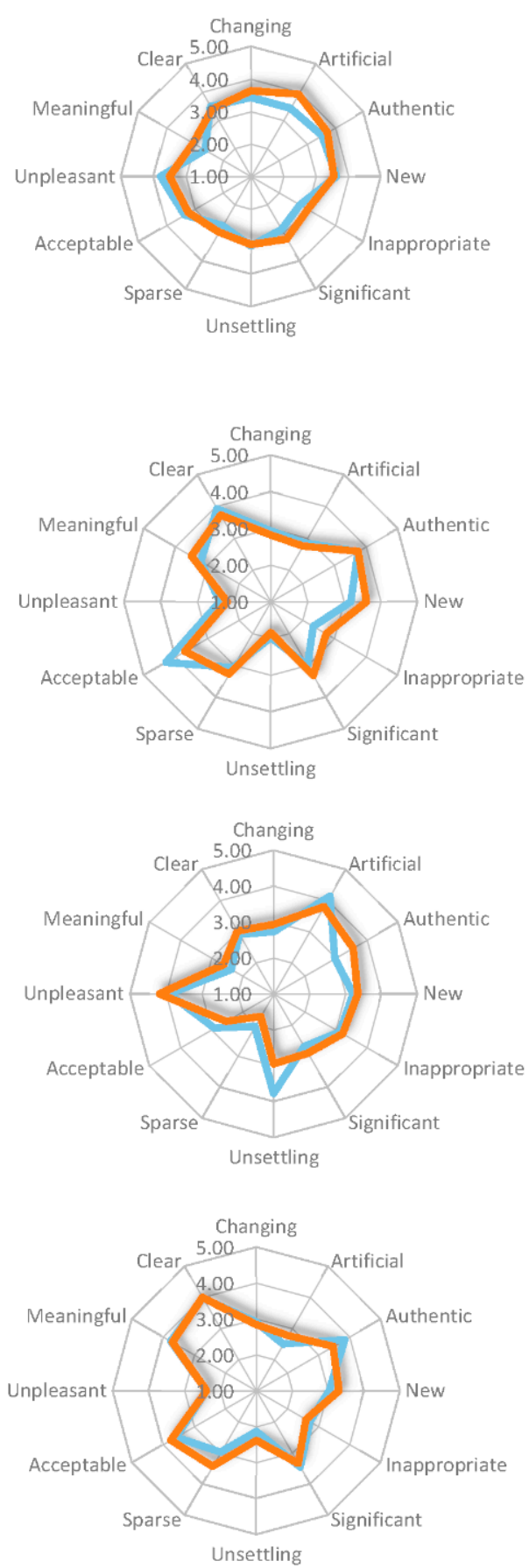

Figure 8. Web charts of average ratings given by study participants divided by age groups on their first (blue) and second (orange) visits to study points, where 1 is the center-point of each web (C P. Jordan): (a) "Mundt"; (b) "Deathstrip"; (c) "West Wall"; (d) "East Wall". 


\section{Discussion}

The survey results indicated that learning about past soundscape conditions can influence perception of historic environments. The noted shifts throughout the soundwalk should not be interpreted as a suspect distortion of results, a mere product of conditioning participants through suggestion and prompting. First, the variability in how participants shifted their perception suggests an internalization of the terms used and an effective grappling with varying conditions. Respondents did not simply mark every study point as more meaningful or significant after hearing historical information. Moreover, in a pedagogical, commemorative context of national memorialization, the process of "re-viewing" (or in this case, "re-hearing") the site as a result of added historical context is a preferred if not characteristic result of a visit. Shifts in awareness about historic realities is a function of memorials. The soundwalk's focus on historic experience easily melded with typical visitor patterns of information assimilation; the soundwalk study results cannot be understood in isolation from the site and standard modes of interaction.

The choice to focus on qualitative analysis was informed by the predominantly textual nature of the data as well as the limited number of participants, with the intent that results could function as preparatory or generalization models for further quantitative analysis and conclusions [30,31]. Looking at the findings of the survey specifically, the gathered data exposed a problematized dialogue between positive perceptions and historic soundscapes that challenges the research trends of the field over time. One of the early concerns of the field was noise, particularly people's adverse reactions to it within urban contexts and how to conceive "better" soundscape experiences. In the past twenty-five years since the reprinting of Schafer's original soundscape work [6], the language and concepts that undergird many soundscape studies have been bound by ideas of human preference (see References [32-38]). For example, research approached the study of noise with an implicit connection between quiet conditions and feelings of pleasantness [23]. A recent shift in the field, owing much to the COST Action TD-0804 Soundscape of European Cities and Landscape project and the introduction of the ISO soundscape standards [3,4,37,39], refocused research attention towards considering all sound as a potential asset rather than simply investigating in opposition to noise. This reframing is important towards broadening the applicability of research results generally and for the Memorial research especially.

The survey results suggested the possibility that the meanings and values associated with historic sites could sway typical soundscape interpretations. The seemingly dependable application of standard soundscape descriptors, such as the terms natural and appropriate, could be destabilized when applied in certain historic scenarios at the Memorial. The terms could even be rendered unusable. Thus, the Memorial study offers a particular challenge to the implicit bias of framing noise in opposition to perceived-pleasant conditions. Despite the location's ostensible similarities to urban parks-for instance, large open spaces dominated by grass crossed by gravel pathways, proximity to urban density, indications of respite such as benches, streetscape barriers (walls) and audible birdsong-it was critical not to extend the assumptions behind urban park soundscape research directly to the Memorial landscape $[38,40]$. This is because the motivations behind visiting historic sites are not solely guided by the search for a pleasant or enjoyable experience $[39,41]$. Such a visit could seek out education and leisure, involving emotions ranging from duty to curiosity, animosity, patriotism, trauma, pride or shame. The respite offered by a bench in the Memorial setting may not be from the intensity of the urban environment but from the emotional demands of traumatic history recall. Typical assumptions concerning the impact of basic physical and sonic elements must be reexamined at a memorial. It stands to reason that the subsequent interpretation of the landscape-and soundscape-may be influenced by these factors as well, which would affect one's classification of a positive experience in historic contexts. An experience involving incredulity, shame, and leisure simultaneously might be positive while not necessarily pleasant. Moreover, the motivations in creating and presenting a memorial are likewise multifaceted and require consideration in historic soundscape analysis; as discussed earlier, they are active constructs of visitor experience of the site and the resulting soundscape. Therefore, 
applying established soundscape descriptors derived from investigations of positive or negative experience has the potential of being inadequate or even misleading.

The West Wall study point provides a good example of the complexities in applying standard terminology in historic soundscapes. As shown in Figures $5 \mathrm{c}$ and $7 \mathrm{c}$, the soundscape at this location was rated on average more natural/ less artificial on the second visit. Typical use of the term natural in soundscape research denotes a relationship with the natural world: animal life, plant growth and favorable meteorological conditions. Describing the environment as natural is striking given the hardscaping of stone-slab sidewalk bordered by a tall concrete wall, paved busy road and multi-story stuccoed buildings. But discussions with participants plus notations on surveys revealed that some participants found the soundscape more "naturally historic" rather than constructed or imposed. Natural and artificial were interpreted and applied differently in the historic setting of the Memorial, particularly after more historic information was conveyed. This was not true at all study points, where associations with nature (particularly birdsong) dominated participant impressions and use of the term. This raises the possibility of descriptors hosting starkly different interpretations by various participants throughout an entire study or even fluctuating between different points by the same participant. It is also important to consider the results in Table 3 concerning the use of the Natural-Artificial scale, where female participants skipped the term slightly more on the second visit than the first throughout the study. If the historic context of the study site destabilized the term natural for participant perception, particularly female respondents, one option to avoid confusion may be to define terms as concretely as possible in advance of soundwalks. Alternatively, using different semantic pairings on the same survey, such as Natural-Artificial, Natural-Unnatural and Natural-Humanmade, might be a way of honing the meaning of terms more specifically. Generally speaking, the West Wall example underscores the necessity of reexamining standard descriptive terms in settings that could evoke multiple associations - consistency with research results gathered across different site environments should not be assumed.

It appears important to factor in the historic background of study sites, both as a general contextual layer and as potential influence on participants' personal experience during the study. The results underscore how important it is for soundscape researchers to constantly revisit the terminology used in survey-based soundscape studies and include ways to capture and interpret the more flexible approach to soundscape interpretation held by some participants. The free-response questions included in this study present only the first step, as not every participant took the opportunity to reflect directly on their experience-some simply described their hunger levels or their competing thoughts. There may be some value in adding a question that prompts participants to reflect on their own results more directly, either at each study point or at the very end of the soundwalk.

Another point of consideration is raised by looking at the differences between age groups depicted in Figure 8. Here, the impressions of respondents with a possible living memory of the Wall did not seem to change with added historic information in comparison to the younger group. The exception, again, is the West Wall point, though the impressions of the older age group only changed mildly. It is too simplistic to suggest that age defines one's historic experience and awareness and thus is the only factor here; however, these results point to an interplay of age and historic interpretation that may be specific to heritage spaces.

Lastly, the results of the Memorial study must be understood within the limits of the participant mix, both in terms of number and background characteristics. Many more participants would be needed to identify cross-demographic trends in the survey data. Living witnesses in particular would require more robust representation, in turn requiring a thoughtful translation of the soundwalk and survey into German rather than English. With more survey responses to scrutinize, biases related to confirmation, valorization and expectation would require examination to contextualize shifts between first and second visits. But taken as a whole, the current study points out discreet hypotheses on the connection of historic soundscapes and soundscape analysis that are open to future comparative research. The intricate relationship of soundscape and historical context cannot be simplified or 
easily categorized solely by pre-existing soundscape practices. As cultural heritage begins to embrace embodied (sonic) experience as vital to historic context, it is equally important that soundscape study begins to incorporate more than the present tense directly in its contextual investigations.

\section{Conclusions}

The study at the Memorial demonstrated a practical methodology for using archival sources to learn about historic soundscape conditions over time as well as integrating this information into participant-based field research via soundwalks and surveys. The mapping study of present conditions helped to visualize the varied sonic conditions that define the primary soundscape relationships throughout the Memorial. Both of these research efforts provided information used directly in the composition of the soundwalk and survey, which sought to identify and explore relationships between historic sonic realities and current historic experience. Further, the project probed whether the soundscape tools commonly employed across soundscape research were readily applicable to investigations within a designated (officially recognized) heritage location. The results of the semantic scalar survey were analyzed qualitatively to identify any patterns in participant use of provided descriptors. This information was cross-referenced for corroborative context with informal conversations and observations from the soundwalks as well as the free-responses and annotations provided by participants on their survey sheets.

The results indicate that historic realities and events can form a vital layer of contextual information that require directed integration into soundscape studies. Moreover, it was shown that the terms and approaches proposed for standardized soundscape investigations are not necessarily equipped to assess historic contextual influence. Soundwalks structured with historic context in mind, like the case study presented here, may prove vital for studying historic soundscapes and how people conceive of history embodied by sound; but they also hold potential as a mechanism of education for the Memorial and other historic places as well. This overlap suggests a partial answer to the challenge of expanding the impact of soundscape study into other fields [32,33,40,41]. But in order to be a viable tool in both soundscape research and heritage applications, the composition of the survey and/or soundwalk must be tuned specifically to the site, its history and current intent.

Funding: This research was funded by the Alexander von Humboldt Foundation and the HEAD Genuit Foundation.

Acknowledgments: The author wishes to thank the Berlin Wall Foundation and Berlin Wall Memorial for research and support assistance, particularly Lydia Dollmann, Axel Klausmeier and Manfred Wichmann. Translation of Zeitzeuge transcripts and research assistance was also provided by Tessa Smith. Brigitte Schulte-Fortkamp, Klaus Genuit, and André Fiebig provided essential suggestions for soundscape analysis. Lastly, the anonymous participants and their dedicated interest throughout each soundwalk made the research both possible and consistently rewarding, for which the author is especially grateful.

Conflicts of Interest: The author declares no conflict of interest. The funders had no role in the design of the study; in the collection, analyses, or interpretation of data; in the writing of the manuscript, or in the decision to publish the results.

\section{References}

1. Bruce, N.S.; Davies, W.J. The effects of expectation on the perception of soundscapes. Appl. Acoust. 2014, 85, 1-11. [CrossRef]

2. Liu, A.; Wang, X.L.; Liu, F.; Yao, C.; Deng, Z. Soundscape and its influence on tourist satisfaction. Serv. Ind. J. 2018, 38, 164-181. [CrossRef]

3. International Organization for Standardization. ISO 12913-1:2014—Acoustics—Soundscape Part 1: Definition and Conceptual Framework; International Organization for Standardization: Geneva, Switzerland, 2014.

4. International Organization for Standardization. ISO 12913-2:2018-Acoustics-Soundscape Part 2: Data Collection and Reporting Requirements; International Organization for Standardization: Geneva, Switzerland, 2018.

5. Truax, B. Sound, listening and place: The aesthetic dilemma. Organ. Sound 2012, 17, 193-201. [CrossRef] 
6. Schafer, R.M. The Soundscape: Our Sonic Environment and the Tuning of the World, 2nd ed.; Destiny Books: Rochester, VT, USA, 1994.

7. Jordan, P. Soundscapes in historic settings-A case study from ancient Greece. In Proceedings of the INTER-NOISE 2016-45th International Congress and Exposition on Noise Control Engineering: Towards a Quieter Future, Hamburg, Germany, 21-24 August 2016. [CrossRef]

8. Holter, E.; Muth, S.; Schwesinger, S. Sounding out Public Space in Late Republican Rome. In Sound and the Ancient Senses, 1st ed.; Butler, S., Nooter, S., Eds.; Routledge: London, UK, 2019; pp. 44-60.

9. Stoever-Ackerman, J. Splicing the Sonic Color-Line. Soc. Text 2010, 28, 59-85. [CrossRef]

10. Schulte-Fortkamp, B.; Jordan, P. When soundscape meets architecture. Noise Map. 2016, 3, 216-231. [CrossRef]

11. Klausmeier, A.; Schmidt, L. Wall Remnants_Wall Traces: The Comprehensive Guide to the Berlin Wall, 1st ed.; Westkreuz-Verlag Gmbh: Berlin/Bonn, Germany, 2005.

12. Gedenkstätte-Berliner-Mauer, Stiftung Berliner Mauer Zieht Positive Bilanz. 2017. Available online: https://www.berliner-mauer-gedenkstaette.de/de/presse-17,250,16.html (accessed on 20 January 2019).

13. SenStadtWohn, 06.06 Population Density. 2016. Available online: https://www.stadtentwicklung.berlin.de/ umwelt/umweltatlas/ekm606.htm (accessed on 20 January 2019).

14. Baker, F. The Berlin Wall: production, preservation and consumption of a 20th-century monument. Antiquity 1993, 67, 709-733. [CrossRef]

15. Verheyen, D. Commemorating a Vanishing Monument. In United City, Divided Memories? Cold War Legacies in Contemporary Berlin; Lexington Books: Lanham, MD, USA, 2008; pp. 219-232.

16. Gröschner, A.; Messmer, A. Aus Anderer Sicht/The Other View; Hatje Cantz: Berlin, Germany, 2011.

17. Stevens, S.S. A scale for the measurement of a psychological magnitude: loudness. Psychol. Rev. 1936, 43, 405-416. [CrossRef]

18. Zwicker, E.; Fastl, H. Psychoacoustics: Facts and Models, 1st ed.; Springer: Berlin/Heidelberg, Germany, 1990.

19. Brown, L.; Brown, A.L. Soundscapes and environmental noise management. Noise Control Eng. J. 2010, 58, 493-500. [CrossRef]

20. Brown, A.L.; Gjestland, T.; Dubois, D. Acoustic Environments and Soundscapes. In Soundscape and the Built Environment, 1st ed.; Kang, J., Schulte-Fortkamp, B., Eds.; CRC Press: Boca Raton, FL, USA, 2017; pp. 1-16.

21. Xiao, J.; Aletta, F. A soundscape approach to exploring design strategies for acoustic comfort in modern public libraries: a case study of the Library of Birmingham. Noise Map. 2016, 3, 264-273. [CrossRef]

22. Nielbo, F.L.; Steele, D.; Guastavino, C. Investigating Soundscape Affordances through Activity Appropriateness. In Proceedings of the Meetings on Acoustics (ICA), Montreal, QC, Canada, 2-7 June 2013; Volume 19, pp. 1-8. [CrossRef]

23. Jordan, P. Valuing the soundscape-Integrating heritage concepts in soundscape assessment. In Proceedings of the INTER-NOISE 2017-46th International Congress and Exposition on Noise Control Engineering: Taming Noise and Moving Quiet, Hong Kong, China, 27-30 August 2017; pp. 5694-5702.

24. Toepoel, V.; Das, M.; Van Soest, A. Design of web questionnaires: The effect of layout in rating scales. J. Off. Stat. 2009, 25, 509-528. [CrossRef]

25. Murdock, B.B., Jr. The serial position effect of free recall. J. Exp. Psychol. 1962, 64, 482-488. [CrossRef]

26. Botteldooren, D.; Andringa, T.C.; Aspuru, I.; Brown, A.L.; Dubois, D.; Guastavino, C.; Kang, J.; Lavandier, C.; Nilsson, M.E.; Preis, A.; et al. From Sonic Environment to Soundscape. In Soundscape and the Built Environment, 1st ed.; Kang, J., Schulte-Fortkamp, B., Eds.; CRC Press: Boca Raton, FL, USA, 2017; pp. 17-41.

27. Raimbault, M. Qualitative Judgements of Urban Soundscapes: Questionning Questionnaires and Semantic Scales. Acta Acust.United Acust. 2006, 92, 929-937.

28. Rasmussen, K.B.B. Sound propagation over grass covered ground. J. Sound Vib. 1981, 78, 247-255. [CrossRef]

29. Wirth, M.; Horn, H.; Koenig, T.; Stein, M.; Federspiel, A.; Meier, B.; Michel, C.; Strik, W. Sex Differences in Semantic Processing: Event-Related Brain Potentials Distinguish between Lower and Higher Order Semantic Analysis during Word Reading. Cereb. Cortex 2007, 17, 1987-1997. [CrossRef] [PubMed]

30. Fiebig, A. Cognitive Stimulus Integration in the Context of Auditory Sensations and Sound Perceptions. Ph.D. Thesis, Technische Universität Berlin, Berlin, Germany, 2015.

31. Hsieh, H.F.; Shannon, S.E. Three Approaches to Qualitative Content Analysis. Qual. Health Res. 2005, 15, 1277-1288. [CrossRef] [PubMed]

32. Ismail, M.R. Sound preferences of the dense urban environment: Soundscape of Cairo. Front. Archit. Res. 2014, 3, 55-68. [CrossRef] 
33. Cassina, L.; Fredianelli, L.; Menichini, I.; Chiari, C.; Licitra, G. Audio-Visual Preferences and Tranquillity Ratings in Urban Areas. Environments 2017, 5, 1. [CrossRef]

34. Sasaki, M. The preference of the various sounds in environment and the discussion about the concept of the soundscape design. J. Acoust. Soc. Jap. 1993, 14, 189-195. [CrossRef]

35. Miller, N. Understanding Soundscapes. Buildings 2013, 3, 728-738. [CrossRef]

36. Carles, J.L.; Barrio, I.L.; de Lucio, J.V. Sound influence on landscape values. Landsc. Urban Plan. 1999, 43, 191-200. [CrossRef]

37. Kang, J.; Chourmouziadou, K.; Sakantamis, K.; Wang, B.; Hao, Y. (Eds) COST Action: TD0804—Soundscape of European Cities and Landscapes; Soundscape-COST: Oxford, UK, 2013.

38. Filipan, K.; Boes, M.; De Coensel, B.; Lavandier, C.; Delaitre, P.; Domitrovic, H.; Botteldooren, D. The Personal Viewpoint on the Meaning of Tranquility Affects the Appraisal of the Urban Park Soundscape. Appl. Sci. 2017, 7, 91. [CrossRef]

39. Poria, Y.; Butler, R.; Airey, D. Links between Tourists, Heritage, and Reasons for Visiting Heritage Sites. J. Travel Res. 2004, 43, 19-28. [CrossRef]

40. Kang, J.; Aletta, F.; Gjestland, T.T.; Brown, L.A.; Botteldooren, D.; Schulte-Fortkamp, B.; Lercher, P.; van Jamp, I.; Genuit, K.; Fiebig, A.; et al. Ten questions on the soundscapes of the built environment. Build. Environ. 2016, 108, 284-294. [CrossRef]

41. Kang, J.; Aletta, F. The Impact and Outreach of Soundscape Research. Environments 2018, 5, 58. [CrossRef]

(C) 2019 by the author. Licensee MDPI, Basel, Switzerland. This article is an open access article distributed under the terms and conditions of the Creative Commons Attribution (CC BY) license (http://creativecommons.org/licenses/by/4.0/). 